www.jmscr.igmpublication.org

Impact Factor 5.84

Index Copernicus Value: 83.27

ISSN (e)-2347-176x ISSN (p) 2455-0450

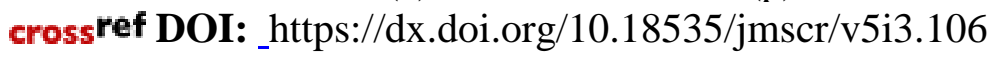

\title{
Original Article \\ Oral Midazolam and Ketamine as Premedicants in Children- A Randomized Open Label Single Centre Study
}

\author{
Authors \\ Bhalerao Pradnya M, MD ${ }^{1}$, Thombre Shalini K., $\mathrm{MD}^{2}$ \\ ${ }^{1}$ Associate Professor, Department of Anaesthesiology.Government Medical College, Miraj \\ ${ }^{2}$ Professor, Department of Emergency Medicine, DY Patil Medical College, Pune \\ Ex Associate Professor ${ }^{[1]}$ and Professor ${ }^{[2]}$, Deartment of Anaesthesiology and Critical Care,B.J Medical \\ College and Sassoon General And Sassoon General Hospitals \\ Corresponding Author \\ Dr Pradnya Bhalerao \\ D-15/10-11, Saritanagari-2, Off, Sinhagad Road, Pune-411030 Maharashtra, India \\ Email: dr.pradnyabhalerao@gmail.com, Tel.No.8806664773
}

\begin{abstract}
Operation theatre and emergency room environment induces fears in a child which include those due to separation from parents, of pain, fear of the unknown and unfamiliar environment and fear due to loss of control and privacy. Pre-medication with anxiolysis and sedation may help to tide over these issues. We thus conducted this study to evaluate the effectiveness of oral midazolam and oral ketamine as premedicants in children.100 children between the age group of 2-8years undergoing surgery lasting 1-1.5hours were considered for this study. The primary objective was to The primary objective was to compare the two in terms of haemodynamic, anxiolysis, and onset and level of sedation. The secondary objective was to look into side effects if any. We found that the two groups were comparable in terms of demographics and haemodynamics. Onset of sedation was faster with midazolam. The sedation score, anxiolysis score, separation from parents score, anxiolysis on venepuncture were similar in both the groups. The side effects, though few, were more in the ketamine group.

Keywords: Oralpremedication, midazolam, ketamine.
\end{abstract}

\section{Introduction}

Surgery and anaesthesia can be a traumatic experience and cause a lot of stress in a child as well as parents. They induce fears in a child which include those due to separation from parents, of pain, fear of the unknown and unfamiliar environment and fear due to loss of control and privacy. These can be prevented by proper psychological preparation and use of appropriate pharmacological adjuncts. An ideal premedicant would be the one which is atraumatic, well accepted, easily administered, acts rapidly, has minimal side effects and does not prolong emergence from anaesthesia. ${ }^{[1]}$

Midazolam is an imidazobenzodiazepine that is given in the oral dose of $0.5-0.75 \mathrm{mg} / \mathrm{kg}$. It has a short half-life of 1-2 $\mathrm{h}$, high potency, twice that of diazepam besides a rapid onset of action (within 
10-30 $\mathrm{min})$. It has sedative and anxiolytic activities, provides anterograde amnesia, and also has anticonvulsant properties. Ketamine, on the other hand, is a 2-0-chlorophenyl 2-methylamine cyclohexine hydrochloride that is given in the oral dose of $3-10 \mathrm{mg} / \mathrm{kg}$. The onset of action is rapid, around 30 minutes. Ketamine provides welldocumented anesthesia and analgesia. It has a wide margin of safety, as the protective reflexes are usually maintained. We thus compared the two drugs as premedicants in our study. ${ }^{[2]}$

The primary objective was to compare the two in terms of haemodynamics, anxiolysis, and onset and level of sedation. The secondary objective was to look into side effects if any.

\section{Material and Methods}

This randomized, open labeled, single centre study was conducted in a tertiary care centre after ethical committee approval. A written informed consent from parents of the child was taken. Children with history of allergy to any of the drugs used in the study as well as children receiving anticonvulsants, sedatives or analgesics in the preoperative period were excluded from the study. 100 children belonging to ASA grade I - II, age 2 to 8 years, of either sex and posted for elective surgery lasting 1 to $1 \frac{1}{2} \mathrm{hrs}$ were considered for the study. They were divided into two $\sqrt{ }$ groups of 50 each by computerised randomization. Group I received oral midazolam $0.5 \mathrm{mg} / \mathrm{kg}$ and group II received oral ketamine $5 \mathrm{mg} / \mathrm{kg}$ body weight both mixed with orange fruit crush 45minutes prior to surgery. Pulse rate, blood pressure and respiratory rate were monitored prior premedication, at 15 minutes and 45 minutes post premedication. Oxygen saturation was monitored throughout. Besides this onset of sedation, level of sedation (Sedation score), acceptance of premedication (Acceptance score),state of anxiolysis (Anxiolysis score) at separation from the parents score and venepuncture and side effects like vomiting, nystagmus, secretions and hallucinations were monitored. Both the groups were given general anaesthesia thereafter.
Statistical analysis was done using SPSS (SPSS 21st edition; IBM Corp, NY) computer program. Statistical calculations were performed by t-test or Mann-Whitney for continuous variables, and by Fisher exact test for discrete variables. $\mathrm{P}$ values $<0.05$ were considered statistically significant.

\section{Results}

As far as the demographic data was concerned the two groups were comparable [Table1].There was a fall in the pulse rate from before premedication values in group I but rise in Group II at 15 followed by some fall though not below prepremedication values at 45 minutes both [Figure1]. Similarly the systolic blood pressure was lower in Group II at 15 and 45 minutes both. There was significant change in the diastolic blood pressure pre and post medication [Figure2, 3]. The onset of sedation was 25 minutes in group I and 31 minutes in groupII [Figure6].The sedation score was good in $60-70 \%$ children in group I and 70$80 \%$ in group II(TableI,Figure7). Sedation score of 3 was achieved in over $90 \%$ patients in both the groups [Figure7].The anxiety on separation score was 1 in $62 \%$ patients in group I and $60 \%$ in group II [Table2, Figure8]. Successful separation was noted in $80 \%$ patients in group I and $76 \%$ in group 2 [Table4, Figure9]. The anxiety on venepuncture score was 1 in $56 \%$ in groupI and $52 \%$ in groupII (Table3, Figure 10 ). $4 \%$ of children had vomiting in group I and $8 \%$ in groupII.12\% had secretions and 4\% nystagmus in Group II.

Table 1: Sedation score ${ }^{[1]}$

1. Agitated (clinging to parents or crying)

2. Awake (alert but not clinging to the parents, may whimper but not cry, anxious)

3. Sleeping intermittently (relaxed, less responsive)

4. Asleep (response to minor stimulation, e.g. light touch, soft voice)

5. Barely arousable (arousable by persistent stimulation needs shaking or shouting to arouse) 
Table 2: Anxiolysis score
1. Combative
2. Tearful / crying
3. Apprehensive
4. Calm

Table 3: Anxiolysis for venepuncture

1. Calm to venepuncture, no reaction, haemodynamically stable

2. Apprehensive venepuncture possible without much difficulty

3/4. Venepuncture difficult, anxious

Table 4: Separation from parents Score

Score 1 : Excellent, happily separated

Score 2 : Good, separated without crying

Score 3 : Separated with crying

Score 4 : Need for restrain

Table 5: Acceptance score

1: Readily accepts

2: Dislikes but accepts

3: Head down / force to accept

4 : Refused to open mouth after tasting premedication

\section{Results}

Table 5 : Demographic data

\begin{tabular}{|l|l|l|l|l|}
\hline Ketamine & 29 & 21 & $6.2 \pm 2.8$ & $\mathrm{p}>0.05$ \\
\hline \hline Drug & Sex & & Age/years & $\mathrm{p}$ value \\
\hline & Male & Female & & \\
\hline Midazolam & 32 & 18 & $5.8 \pm 2.3$ & $\mathrm{p}>0.05$ \\
\hline Ketamine & 29 & 21 & $6.2 \pm 2.8$ & $\mathrm{p}>0.05$ \\
\hline
\end{tabular}

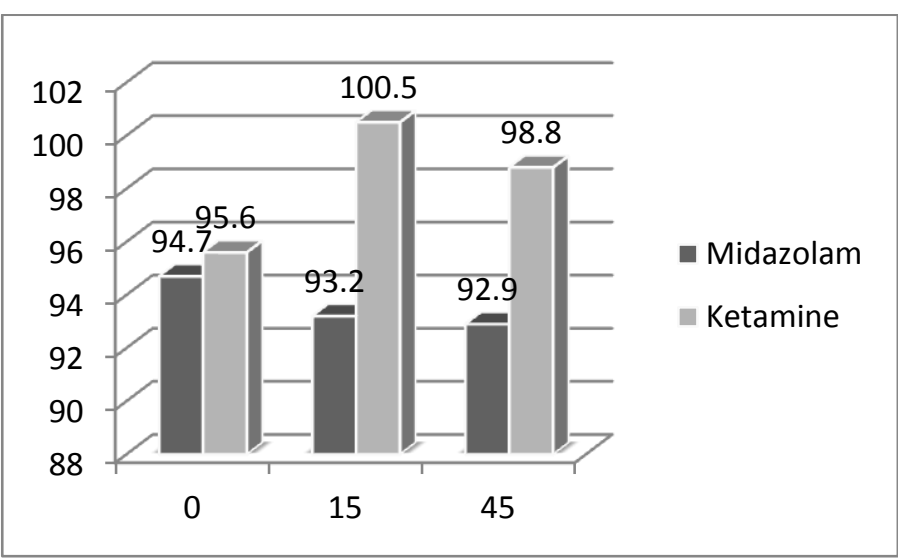

Figure 1 : Pulse rate , $\mathrm{p}<0.05$-not significant

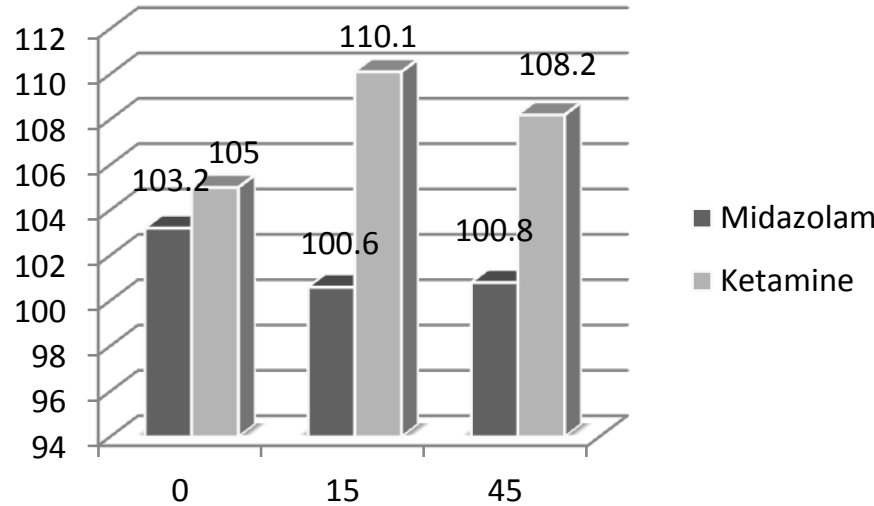

Figure 2: Systolic blood pressure ( $\mathrm{mm} \mathrm{Hg}$ ), $\mathrm{p}<0.05$-not significant

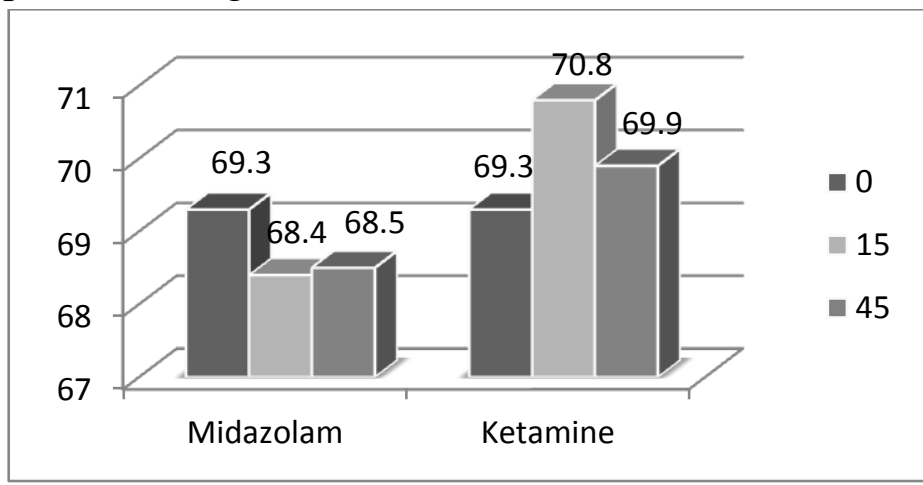

Figure 3: Diastolic blood pressure ( $\mathrm{mm} \mathrm{Hg}$ ), $\mathrm{p}<0.05$-not significant

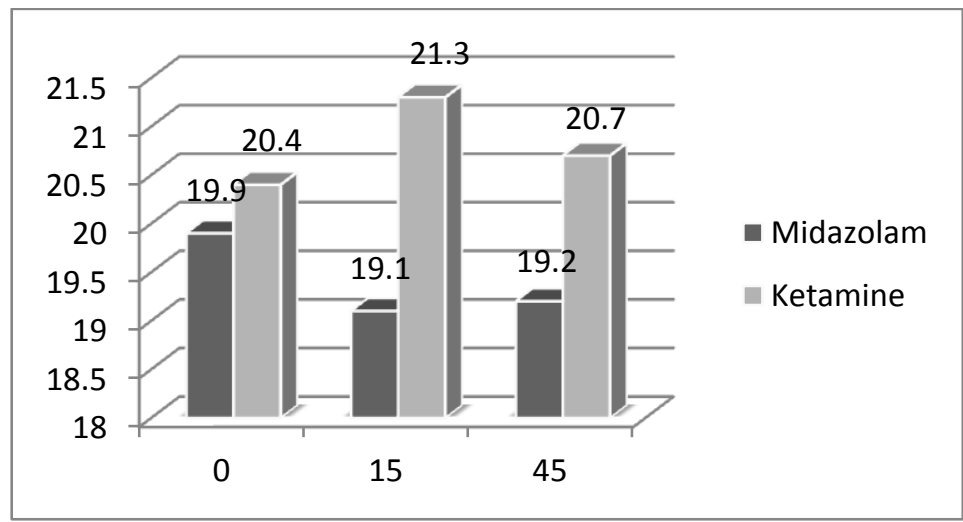

Figure 4 : Respiratory rate/minute, $p<0.05$-not significant

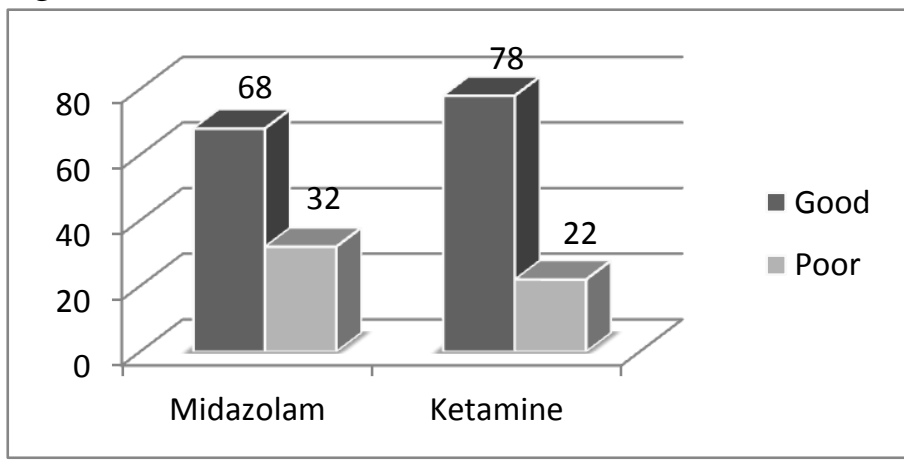

Figure 5:Acceptance score 


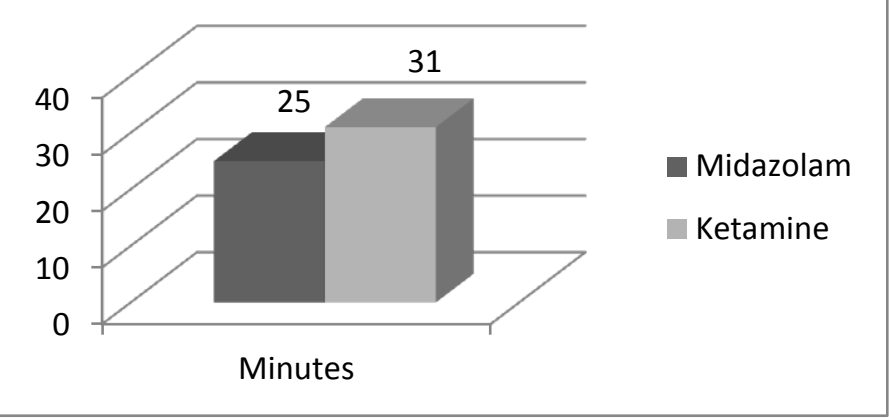

Figure 6 : Onset of sedation

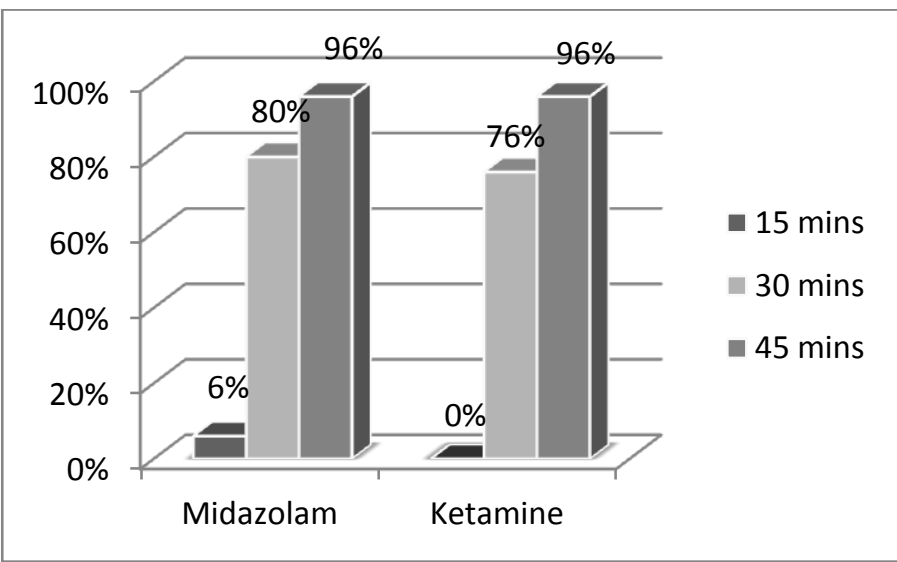

Figure 7 : Level of sedation

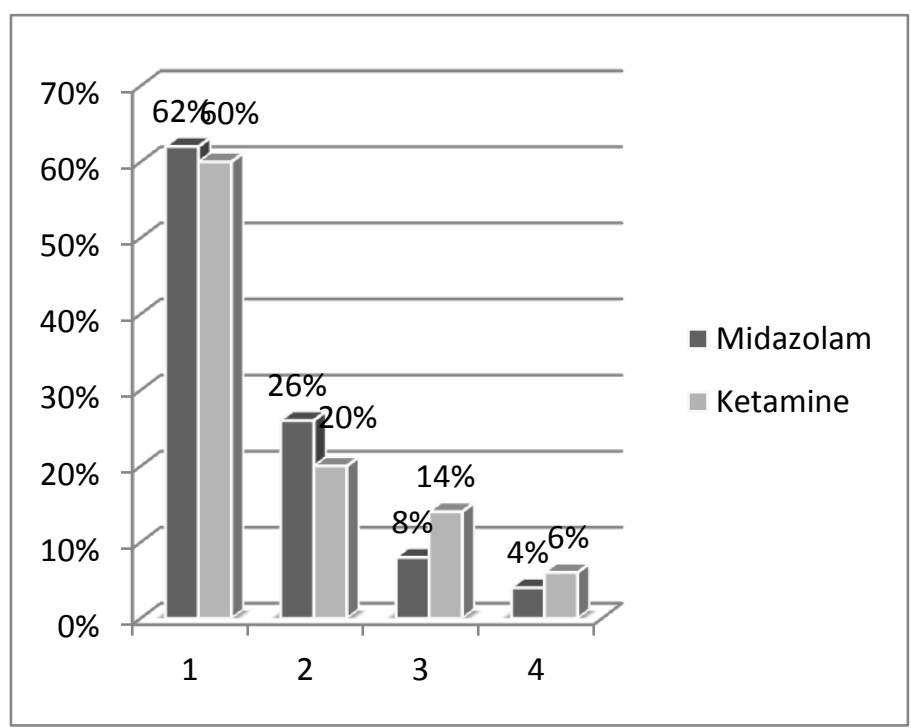

Figure 8 : Anxiolysis on separation

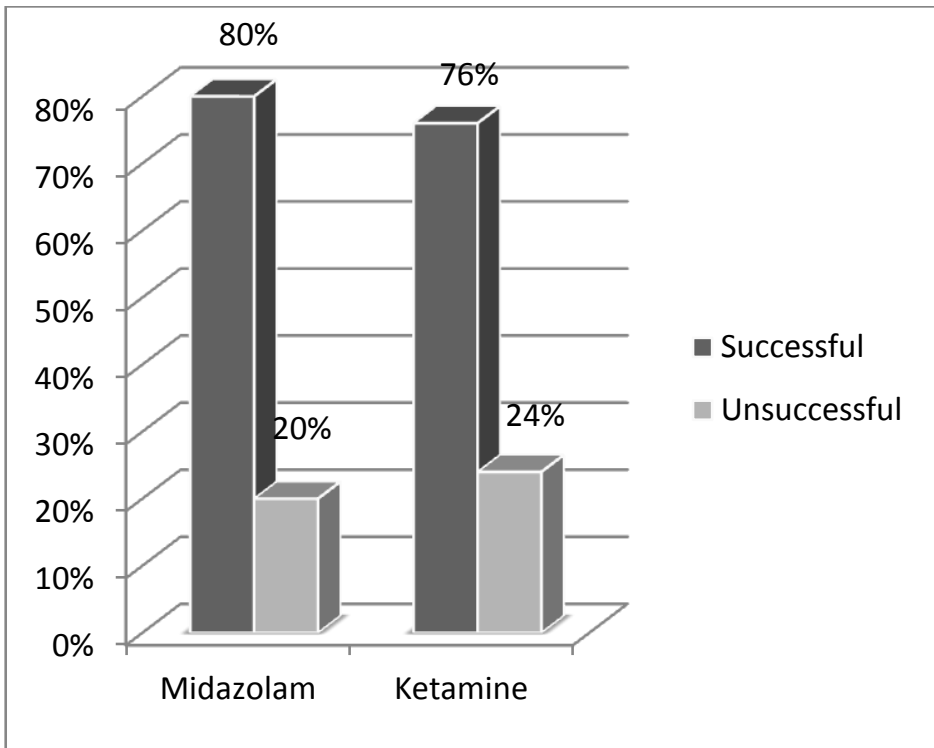

Figure 9 : Separation from parents score

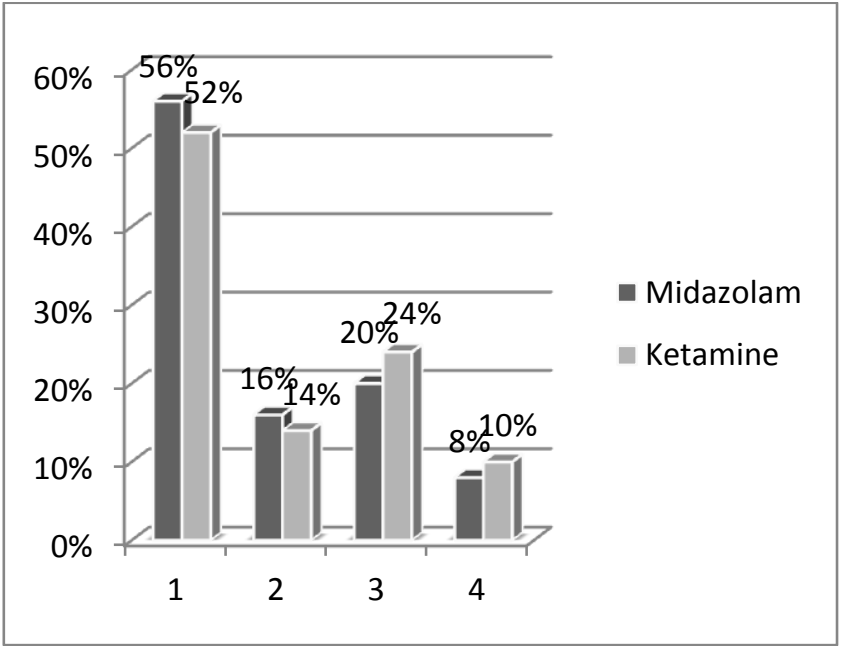

Figure 10 : Anxiolysis on venepuncture

\section{Discussion}

Premedicants can be given by various routes namely oral, intramuscular, intravenous, intranasal, and per-rectal.Injections cause screaming, struggling, bad memories in a child. ${ }^{[3]}$ Intranasal drug can cause a burning sensation and bitter taste in the pharynx. The per-rectal route can be psychologically embarrassing, besides causing unreliable absorption. Therefore oral premedication in children is definitely a good alternative.

The oral route causes the least anxiety in young children. Oral chloral hydrate has long been used for paediatric sedation for painless procedures, but the onset of sedation may be delayed and a prolonged recovery time is common. 
The oral drug should be palatable. Since midazolam has a bitter taste fruit syrup was mixed with both to tide over this pitfall. Since the time to onset of sedation in both groups is about 30minutes the drug was given 45 minutes prior scheduled anesthesia induction.

A dose of $0.5 \mathrm{mg} / \mathrm{kg}$ midazolam and $5 \mathrm{mg} / \mathrm{kg}$ ketamine was used in our study. Higher doses of midazolam and ketamine have been used in other studies. $^{[4,5]}$

As far as the haemodynamic parameters were concerned in the midazolam group stability was better thoughout. In the Ketamine group there was an initial rise in pulse rate and blood pressure at 15 minutes followed by fall to normal basal values. This was however both statistically and clinically insignificant. The respiratory rate was not significantly altered in both groups [Figure 4]. Ketamine has been proven to be effective as an analgesic and amnesic when administered by the intravenous, intramuscular, and intranasal routes. Its efficacy upon oral administration was examined in various procedures, such as dental procedures, wound dressing in burns. ${ }^{[5]}$ Onset of sedation was faster with midazolam in our study. The level of sedation score $>3$ was achieved similarly in both the groups at 45 minutes.Studies have shown that achieving adequate sedation was more common in children treated with the combination of ketamine and midazolam rather than oral midazolam alone. ${ }^{[6,7,8]}$ Procedural sedation was adequately achieved with fentanyl and midazolam combination in one study. ${ }^{[9]}$ Separation from parents was equally good in both groups however anxiolysis on venepuncture was poor in $28 \%$ and $34 \%$ cases with midazolam and ketamine respectively. Rubinstein found that supplementation with intravenous drug was more in the ketamine group. ${ }^{[5]}$

The two drugs have been used safely in paediatric dental procedures in the doses similar to those on our study with apparently better outcomes with midazolam. ${ }^{[2,10]}$

Thus both oral midazolam and ketamine were cardiorespiratory stable. Ketamine was better accepted probably because the bitter taste of midazolam was not completely masked [Figure5]. Faster onset of sedation was seen with midazolam. Level of sedation and anxiolysis was comparable. Emesis and secretions was more with ketamine and was seen in a nystagmus in few with oral ketamine.

The limitation with use of these drugs orally is the decrease in bioavailability due to first pass effect with both the drugs, more so with midazolam.

\section{Conclusion}

Oral midazolam and ketamine are good premedicants in children with adequacy in level of sedation and anxiolysis. The anterograde amnesia with midazolam could be an added advantage. Combining midazolam and ketamine could be an option.

Source(s) of support: Nil

Presentation at a meeting: No

Conflicting Interest (If present, give more details):Nil

\section{References}

1. R Remadevi, P Ezhilarasu, L Chandrasekar, A Vasudevan. Comparison of Midazolam and Ketamine as Oral premedicants in pediatric patients. The Internet Journal of Anesthesiology. 2008; 21( 2):17.

2. Damle SG, Gandhi M, Laheri V. Comparison of oral ketamine and oral midazolam as sedative agents in pediatric dentistry.J Indian Soc Pedod Prev Dent. 2008 Sep;26(3):97-101.

3. Ozdemir D, Kayserili E, Arslanoglu S, et al. Ketamine and midazolam for invasive procedures in children with malignancy: a comparison of routes of intravenous, oral and rectal administration. J Trop Pediatr 2004;50:224-8.

4. Younge PA, Kendall JM. Sedation for children requiring wound repair: a randomized controlled double blind 
comparison of oral midazolam and oral ketamine. Emer Med J 2001;18:30.

5. Rubinstein et al Efficacy of oral ketamine compared to midazolam for sedation of children undergoing laceration repair .A double-blind, randomized, controlled trial. Medicine. 2016; 95:26.

6. Jain K, Ghai B, Saxena AK, et al. Efficacy of two oral premedicants: midazolam or a low dose combination of midazolamketamine for reducing stress during intravenous cannulation in children undergoing CT imaging. Pediatr Anaesth 2010;20:330-7.

7. Dilli D, Dallar Y, H.Sorgui N. Comparison of Ketamine plus midazolam Versus Ketamine for sedation in children during lumbar puncture. Clin J Pain 2009;25:34950.

8. Barkan S, Breitbart R, Brenner-Zada G, et al. A double-blind, randomised, placebocontrolled trial of oral midazolam plus oral ketamine for sedation of children during laceration repair. Emerg Med J 2014;31:649-53.

9. McQueen A, O. Wright R, M. Kido M, et al. Procedural sedation and analgesia outcomes in children after discharge from the emergency department: Ketamine versus Fentanyl/Midazolam. Ann Emerg Med 2009;54:191-7.

10. Rai K, Hegde AM, Goel K. Sedation in uncooperative children undergoing dental procedures: a comparative evaluation of midazolam,propofol and ketamine. J Clin Pediatr Dent 2007;32:1-4. 